\title{
Splenic autotransplantation in a patient with human immunodeficiency virus infection: a case report
}

\author{
Adriana Toro, Maurizio Mannino, Giulio Reale and Isidoro Di Carlo*
}

\begin{abstract}
Introduction: Splenectomy is performed mostly because of traumatic events that cause rupture of the spleen. Postsplenectomy, a patient has a higher risk of developing sepsis. Autotransplantation of splenic tissue decreases the risk of opportunistic infection and sepsis, but its role in patients with human immunodeficiency virus is debated because the spleen is a replication site, especially during the asymptomatic phase of this infection. We present a case of a patient with human immunodeficiency virus infection who was admitted to our hospital for a traumatic rupture of the spleen and underwent spleen autotransplantation.
\end{abstract}

Case presentation: A 36-year-old Caucasian man was admitted to the shock trauma center of our hospital after a car accident. Anamnesis showed that the patient had been human immunodeficiency virus-positive for 13 years. A computed tomography scan showed abundant fluid collection in his superior and inferior abdomen caused by splenic rupture, with no other associated intra-abdominal lesions. During surgery, the spleen appeared severely damaged. A splenectomy was performed, and $35 \mathrm{~g}$ of splenic tissue was autotransplanted in a pouch created in the omentum. No complications occurred after surgery, and our patient was discharged from our hospital nine days after the operation. One year later, computed tomography and scintigraphy showed that the transplanted tissue was functioning well.

Conclusions: Autotransplantation of splenic tissue decreases the risk of opportunistic infection and sepsis, and it might also be useful in patients with human immunodeficiency virus. Other studies need to be done to validate this hypothesis.

\section{Introduction}

Splenectomy is performed mostly because of traumatic events that cause rupture of the spleen [1]. Postsplenectomy, a patient is at a higher risk of developing sepsis [2]. In patients with human immunodeficiency virus (HIV) infection, a splenectomy can be performed to treat related thrombocytopenia. Autotransplantation of splenic tissue decreases the risk of opportunistic infection and sepsis, but its role in patients with HIV is debated because the spleen is a replication site, especially in the asymptomatic phase of this infection [3]. However, previous reports in the literature have shown that HIV DNA, mostly transported by $\mathrm{CD}^{+}{ }^{+} \mathrm{T}$

\footnotetext{
* Correspondence: idicarlo@unict.it Department of Surgical Sciences, Organ Transplantation, and Advanced Technologies, University of Catania, Cannizzaro Hospital, Via Messina 829, I95126 Catania, Italy
}

(c) 2011 Toro et al; licensee BioMed Central Ltd. This is an Open Access article distributed under the terms of the Creative Commons Attribution License (http://creativecommons.org/licenses/by/2.0), which permits unrestricted use, distribution, and reproduction in any medium, provided the original work is properly cited. lymphocytes, can be found in the spleen. It seems that, on the basis of these studies, splenic dendritic cells can harbor the virus, but it is not likely that they can be used as a major replication site in the course of the disease [4].

HIV also directly damages splenic tissue, reducing white pulp and causing perivascular hyalinization, infarcts, necrosis and granulomatous reactions [5], but germinal centers continue to function even when infiltrated by the virus [6]. Therefore, performing a splenectomy in patients with HIV can be considered as both a positive treatment and a risk, because it eliminates a possible source of infection while weakening the already compromised immune system of these patients.

This case report discusses the case of a patient with splenic trauma that was treated successfully with autotransplantation of splenic tissue. We describe how a 
transplant technique involving only a small amount of splenic tissue inserted into a single pouch in the omentum can be a valid therapeutic choice in patients with HIV to balance the benefits and disadvantages of splenectomy.

\section{Case report}

A 36-year-old Caucasian man was admitted to the shock trauma center of our hospital after a car accident. Anamnesis showed that our patient had been HIV-positive for 13 years. No other information about our patient was available at that time, because he was in a life-threatening condition and no time was available to ask for information from the infectious disease specialist engaged in treating our patient's HIV.

Laboratory tests showed an increased number of leukocytes $\left(12.3 \times 10^{3} / \mu \mathrm{L}\right.$; reference range, 4.1 to $10.9 \times$ $10^{3} / \mu \mathrm{L}$ ), mostly neutrophils; and high levels of lactate dehydrogenase (778 U/L; reference range, 300 to $600 \mathrm{U} /$ $\mathrm{L}$ ), creatine kinase (372 U/L; reference range, 38 to 190 $\mathrm{U} / \mathrm{L})$ and aspartate aminotransferase $(63 \mathrm{U} / \mathrm{L}$; reference range, 13 to $41 \mathrm{U} / \mathrm{L}$ ). His hemoglobin, red blood cells, and hematocrit were within the reference ranges.

A computed tomography (CT) scan showed abundant fluid collection in his superior and inferior abdomen caused by splenic rupture, with no other associated intra-abdominal lesions. Surgery was acutely scheduled after we acquired our patient's informed consent. During surgery, his spleen appeared severely damaged on the surface, necrotic and extremely congested. A splenectomy was performed, and $35 \mathrm{~g}$ of splenic tissue was autotransplanted into a pouch created in the omentum.

No complications occurred after surgery, and our patient was discharged nine days after the operation. One year later, CT and scintigraphy showed that the transplanted tissue was functioning well.

\section{Discussion}

Conservative treatment after splenic trauma has been suggested due to the association of sepsis and thromboembolic complications after splenectomy [7]. In patients with splenic trauma, autotransplantation is also performed in addition to the conservative treatment methods and nonoperative management.

Saving splenic tissue is important because of the role of the spleen in the immune system; asplenia is often related to a higher risk of sepsis or infections, particularly those caused by encapsulated bacteria such as Neisseria meningitidis or Streptococcus pneumoniae $[8,9]$. Other lymphoid tissues can respond to recurrent infections, but the spleen is fundamental in the immune response to newly encountered encapsulated bacteria. Therefore, asplenic patients are more vulnerable to new infections caused by these kinds of agents.
Autotransplantation of splenic tissue decreases the risk of opportunistic infection or sepsis, but its role in patients with HIV is debated because in people with HIV the spleen is a replication site, especially in the asymptomatic phase of the disease.

However, previous studies have demonstrated that splenectomy has a positive effect on platelet count in patients with HIV-related immune thrombocytopenia and that splenectomy has beneficial effects because the progression of HIV becomes slower than in patients with spleens [10-12]. A possible explanation for this observation is that the spleen forms approximately $50 \%$ of lymphoreticular tissue. Lymphoreticular tissue represents the major site for HIV sequestration and replication. The spleen is the ideal viral replication site, so the removal of a large proportion of lymphoreticular tissue during splenectomy may reduce the available reservoir for the HIV replication cycle. These studies, however, did not analyze the amount and the types of infections that occur during the asymptomatic phase of HIV.

Although it is pretty certain that splenic dendritic cells can harbor the virus, it is not likely that they can be used as a major replication site by the virus during the course of the disease [4].

Two explanations for the finding of HIV in germinal centers have been reported in the literature. Either the virus can arrive there after being transported on the surface of dendritic cells as an immune complex, or it can be produced in its normal place by HIV-infected antigen-specific $\mathrm{T}$ cells within germinal centers.

Follicular dendritic cells are exclusive structures found in the lymphoid follicles of secondary lymphoid organs. They are involved in the process of maturation of immunoglobulin-producing cells and in the process of B-cell memory, and they are not permissive for HIV infection [13]. Germinal centers, however, continue to function even when infiltrated by the virus and appear to be hyperplastic [6].

In the mouse, one of the targets of HIV is CD27 ${ }^{+}$B220 $\mathrm{B}$ cells, a population of cells of the peripheral blood similar to splenic marginal zone cells. Mouse models have shown that the depletion of $\mathrm{CD} 27^{+} \mathrm{B} 220^{-} \mathrm{B}$ cells is parallel to an alteration in the splenic B-cell population caused by HIV, and this seems to be involved in the defective B-cell immunity against encapsulated bacteria such as pneumococcus [14]. Therefore, the goals of spleen autologous transplantation described in this case report were to avoid this loss of efficiency of the immune system, especially against encapsulated bacteria, and at the same time to reduce to a minimum the risk of preserving a viral reservoir by transplanting a large amount of splenic tissue. For this reason, we did not execute multiple-site transplants in the omentum as is usually reported. In fact, multiple transplants after 
initial necroses may develop into new tissue and become more abundant than the native spleen in the medium or long term, and this condition could increase the active replication of the virus. Therefore, we decided to transplant only $35 \mathrm{~g}$ of splenic tissue into an omental pouch because this quantity is effective in establishing a normal immune system and does not offer the virus a large replication site. One of the methods of performing a splenic autotransplant is to suture small pieces of splenic tissue $(1-2 \mathrm{~cm})$ to the greater omentum or the mesocolon, where the veins drain to the portal vein and the liver. In our patient, we transplanted a single large element with the risk of partial necrosis to avoid the risk of viral replication in multiple elements [15].

As previously discussed, the spleen is the ideal replication site for HIV, but the choice to reimplant splenic tissue should be given high regard, considering that after the operation the patient will have far less tissue than with an entire spleen, so the risk of restoring a good site for major viral replication is drastically reduced.

Splenic autotransplantation affords clinicians the possibility of maintaining the marginal zone, which is an essential part of the spleen involved in the response to encapsulated bacteria and in rapid humoral response to blood-borne antigens [16]. Therefore, performing autotransplantation is useful in building a response to bacteria during a period when HIV does not attack T-cell function and marginal zone function too much. In this way, autotransplantation has the advantage of making use of an eventual secondary response during periods that may follow when immune deficiency becomes important.

\section{Conclusion}

Autotransplantation of splenic tissue decreases the risk of opportunistic infection and sepsis, and its role should be useful in patients with HIV. Other studies are needed to validate this hypothesis.

\section{Consent}

Written informed consent was obtained from the patient for publication of this case report and any accompanying images. A copy of the written consent is available for review by the Editor-in-Chief of this journal.

\footnotetext{
Acknowledgements

The authors thank the patient for allowing us to publish this case report. The authors do not have any financial interests related to the publication of this case report.
}

drafted the manuscript. IDC did critical revision of the manuscript. IDC supervised the study.

All authors have read and approved the final manuscript.

\section{Competing interests}

The authors declare that they have no competing interests.

Received: 21 January 2011 Accepted: 15 August 2011

Published: 15 August 2011

\section{References}

1. Gedik E, Girgin S, Aldemir M, Keles C, Tuncer MC, Aktas A: Non-traumatic splenic rupture: report of seven cases and review of the literature. World J Gastroenterol 2008, 14:6711-6716.

2. Tzoracoleftherakis E, Alivizatos $V$, Kalfarentzos F, Androulakis J: Complications of splenic tissue reimplantation. Ann R Coll Surg Engl 1991, 73:83-86.

3. Tsoukas JM, Bernard N, Abrahamowicz M, Strawczynski H, Growe G, Card RT, Gold P: Effect of splenectomy on slowing human disease immunodeficiency virus disease progression. Arch Surg 1998, 133:25-31.

4. Mcllroy D, Autran B, Cheynier R, Wain-Hobson S, Clauvel JP, Oksenhendler E, Debré P, Hosmalin A: Infection frequency of dendritic cells and CD4+ T lymphocytes in spleens of human immunodeficiency virus-positive patients. J Virol 1995, 69:4737-4745.

5. Diaz LK, Murphy RL, Phair JP, Variakojis D: The AIDS autopsy spleen: a comparison of the pre-anti-retroviral and highly active anti-retroviral therapy eras. Mod Pathol 2002, 15:406-412.

6. Gratton S, Cheynler R, Dumaurier MJ, Oksenhendler E, Wain-Hobson S: Highly restricted spread of HIV-1 and multiply infected cells within splenic germinal centers. Proc Natl Acad Sci USA 2000, 97:14566-14571.

7. Pisters PW, Pachter HL: Autologous splenic transplantation for splenic trauma. Ann Surg 1994, 219:225-235.

8. Timens W, Leemans R: Splenic autotransplantation and the immune system: adequate testing required for evaluation of effect. Ann Surg 1992, 215:256-260

9. Takayasu H, Ishimaru Y, Tahara K, Otani Y, Yamagishi J, Ikeda H: Splenic autotransplantation for a congested and enlarged wandering spleen with torsion: report of a case. Surg Today 2006, 36:1094-1097.

10. Lord RV, Coleman MJ, Milliken ST: Splenectomy for HIV-related immune thrombocytopenia: comparison with results of splenectomy for non-HIV immune thrombocytopenic purpura. Arch Surg 1998, 133:205-210.

11. Oksenhendler E, Bierling P, Chevret S, Delfraissy JF, Laurian Y, Clauvel JP, Seligmann M: Splenectomy is safe and effective in human immunodeficiency virus-related immune thrombocytopenia. Blood 1993, 82:29-32.

12. Forsythe RM, Harbrecht BG, Peitzman AB: Blunt splenic trauma. Scand J Surg 2006, 95:146-151.

13. Dumaurier MJ, Gratton S, Wain-Hobson S, Cheynier R: The majority of human immunodeficiency virus type 1 particles present within splenic germinal centres are produced locally. J Gen Virol 2005, 86:3369-3373.

14. Morrow M, Valentin A, Little $R$, Yarchoan R, Pavlakis GN: A splenic marginal zone-like peripheral blood $C D 27^{+} B 220^{-}$B cell population is preferentially depleted in HIV type 1-infected individuals. AIDS Res Hum Retroviruses 2008, 24:621-633.

15. Petroianu A, Cabezas-Andrade MA, Neto RB: Laparoscopic splenic autotransplantation. Surg Laparosc Endosc Percutan Tech 2006, 16:259-262

16. Zandvoort A, Timens W: The dual function of the splenic marginal zone: essential for initiation of anti-Tl-2 responses but also vital in the general first-line defense against blood-borne antigens. Clin Exp Immunol 2002, 130:4-11.

doi:10.1186/1752-1947-5-379

Cite this article as: Toro et al:: Splenic autotransplantation in a patient with human immunodeficiency virus infection: a case report. Journal of Medical Case Reports 2011 5:379. 